\title{
Erratum to: Surgery of the Skull Base
}

Alexander König and Uwe Spetzger

The updated original online version for this chapter can be found at https://doi.org/10.1007/978-3-319-64018-1_2 https://doi.org/10.1007/978-3-319-64018-1_5 https://doi.org/10.1007/978-3-319-64018-1_6

(c) Springer International Publishing AG 2018 A. König, U. Spetzger (eds.), Surgery of the Skull Base, https://doi.org/10.1007/978-3-319-64018-1_9 


\section{Errata to:}

A. König, U. Spetzger Surgery of the Skull Base, https://doi.org/10.1007/978-3-319-64018-1

We received the following corrections in chapters 2, 5 and 6 and the same has been updated in the book.

Corrections:

1. In chapter 2 , new figure 2.7 was received

2. In chapter 5, new figures $5.46,5.52$ and 5.54 were received

3. In chapter 5, the names of the contributing authors were to be placed under the respective sections in the chapter TOC, chapters and the running heads of the chapter

4. In chapter 6, legend of the box 6.2 was changed to 'Criteria for Primary (Idiopathic) Vestibular Paroxysmia'

5. In chapter 6 , the names of the contributing authors were to be placed under the respective sections in the chapter TOC, chapters and the running heads of the chapter 